Three Kingdoms 



\title{
Three Kingdoms
}

A Historical Novel

ABRIDGED EDITION

\author{
Attributed to \\ Luo Guanzhong
}

Translated from the Chinese by

Moss Roberts

甲 
University of California Press, one of the most distinguished university presses in the United States, enriches lives around the world by advancing scholarship in the humanities, social sciences, and natural sciences. Its activities are supported by the UC Press Foundation and by philanthropic contributions from individuals and institutions. For more information, visit www.ucpress.edu.

University of California Press

Oakland, California

(C) 1999, 2014, 2020 by The Regents of the University of California

ISBN 978-0-520-34455-6 (pbk.: alkaline paper)

ISBN 978-0-520-97666-5 (ebook)

The Library of Congress has cataloged an earlier edition of this book as follows:

Lo, Kuan-chung, ca. 1330-ca. 1400:

[San kuo chih yen i. English. Selections]

Three kingdoms: a historical novel / attributed to Luo Guanzhong: translated from the Chinese with afterword by Moss Roberts.-

Abridged ed.

p. $\mathrm{cm}$.

ISBN 978-0-520-21585-6 (pbk.: alk. paper)

1. China-History-Three Kingdoms, 220-265-Fiction.

I. Roberts, Moss, 1937- II. Title.

PL269O.S3E5325 1998

$895.1^{\prime} 346-\mathrm{dc} 21$

$$
\text { 98-39516 }
$$

CIP

Manufactured in the United States of America

$\begin{array}{llllllllll}29 & 28 & 27 & 26 & 25 & 24 & 23 & 22 & 21 & 20\end{array}$

$\begin{array}{llllllllll}10 & 9 & 8 & 7 & 6 & 5 & 4 & 3 & 2 & 1\end{array}$ 